\title{
Stress Analysis of Three Marginal Configurations of Full Posterior Crowns by Three-Dimensional Photoelasticity
}

\author{
J. W. FARAH and R. G. CRAIG \\ University of Michigan, School of Dentistry, Ann Arbor, Michigan 48104, USA
}

A simplified method was developed by which three-dimensional composite photoelastic models were constructed. The optimum marginal configuration for the stress distribution was determined and was found to be of the chamfer type.

As a result of the complex configuration of a dental restoration, an analysis of internal stresses utilizing the theory of elasticity is extremely difficult to accomplish. The method of photoelasticity, however, appears to be particularly suitable for such occasions. Many investigators have used two-dimensional photoelastic dental models to study, among others, the effects of rounding axiopulpal line angles, as well as the stress distribution associated with the variations of the angle of axial walls. Fewer investigators have used the three-dimensional technique, mainly because of the complications involved in the preparation and analysis of the model and the unavailability of a photoelastic material with a wide range of values of Young's modulus at the stress freezing temperature.

In 1965, Walton and Leven ${ }^{1}$ presented a three-dimensional photoelastic study of an anterior jacket crown. Four models were analyzed and they concluded that the thicker the walls of the jacket, the greater was its strength. They also found that maximum mesiodistal width of the preparation was important.

This investigation was supported by USPHS Research Grant DE-01817 from the National Institute of Dental Research, National Institutes of Health, Bethesda, Md.

Presented at the 50 th general session of the IADR, Las Vegas, Nevada, March 1972.

Based on a portion of a dissertation in partial fulfillment of the $\mathrm{PhD}$ degree in dental materials and aerospace engineering (mechanics) at the University of Michigan, 1972.

Received for publication May 21, 1973.
Johnson ${ }^{2}$ showed that the inclusion of irregularly shaped pulp chambers in threedimensional photoelastic models of mandibular molars did not affect the stress distribution at the base of the cavity. Johnson et al $^{3}$ used three-dimensional photoelastic stress analysis to investigate the design of Class I cavity preparations. The models were made of epoxy resin, and they were tested using the stress freezing technique. They remarked that significant stresses existed in planes remote from points of loading and that rounding internal line angles reduced the stresses significantly.

By use of two-dimensional photoelastic models El-Ebrashi, Craig, and Peyton ${ }^{4-8}$ investigated the effects of modifying the geometry in dental restorations.

In this investigation a method is developed and described which enables one to construct a composite dental model with the proper modulus and Poisson's ratio at the same stress freezing temperature. Threedimensional photoelasticity was used to investigate the effects of varying the geometry of a gold full-crown restoration on the stress distribution in a model of the restoration and the supporting dentin.

\section{Materials and Methods}

Preliminary testing of the photoelasTIC MATERIALS. - The photoelastic material was a two component system, an epoxy resina and an amine hardener, ${ }^{b}$ mixed in the ratio of $2: 1$. This ratio was decided upon after extensive tests on cylindrical specimens with a wide range of resin to hardener ratio ( $\mathrm{Ta}$ ble 1). Once the desired quantity of resin and hardener was established, the compo-

\footnotetext{
Epon 828, Shell Chemical Co., Plastics \& Resins Div., New York, NY.

Jeffamine D400, Jefferson Chemical Co., Austin, Tex.
} 
TABLE I

Resin to HaRdener Composition of Cylindrical Specimens

\begin{tabular}{|c|c|c|c|c|}
\hline $\begin{array}{l}\text { Specimen } \\
\text { No. }\end{array}$ & $\begin{array}{l}\text { No. of } \\
\text { Specimens } \\
\text { Tested }\end{array}$ & Resin & $\begin{array}{l}\text { Hardener } \\
(\mathrm{pph})\end{array}$ & Conclusion \\
\hline 1 & 3 & & 30 & Poor machinability \\
\hline 2 & 4 & & 40 & $\begin{array}{l}\text { Thick mix enhances } \\
\text { formation of air bubbles }\end{array}$ \\
\hline 3 & 8 & & 50 & $\begin{array}{l}\text { Good machinability, } \\
\text { excellent time edge effects }\end{array}$ \\
\hline 4 & 9 & 100 parts & 60 & $\begin{array}{l}\text { As good as specimen no. } 3 \\
\text { except longer cure cycles } \\
\text { required }\end{array}$ \\
\hline 5 & 5 & & 70 & Rubbery, long cure cycles, \\
\hline 6 & 3 & & 80 & and fair to poor machin \\
\hline 7 & 3 & & 90 & ability \\
\hline 8 & 2 & & 100 & Too rubbery \\
\hline
\end{tabular}

nents were gently and thoroughly mixed at room temperature so as to avoid the incorporation of air bubbles. When a clear mixture was obtained the batch was placed under a vacuum of 10 psi for a period of one hour to be sure that the mixture was bubblefree. The mixture then was poured in to cylindrical silicone molds and allowed to polymerize for three days at room temperature, after which time the specimens were placed for 30 minutes in an oven at $140 \mathrm{~F}$ and then allowed to cool to room temperature.

The resulting cylindrical specimens were 1.227 inches in diameter, and their length was trimmed to about 2.0 inches with the help of a flywheelc on which Carborundum cut-off wheels ${ }^{d}$ were mounted. These specimens were then ready to be tested in compression to determine their modulus. The material as has been described will henceforth be referred to as $M-1$.

Other specimens were prepared following the same procedure as described, but subjected to a different curing cycle. After the three-day polymerization the specimens were placed in the oven for two hours at $115 \mathrm{~F}$ and then permitted to cool to room temperature. Following this treatment the specimens were replaced in the oven at $212 \mathrm{~F}$ for two hours and again allowed to cool slowly to room temperature to avoid large thermal gradients. At this time their length was trimmed to approximately 2.0 inches and the specimens were ready to be tested to

c Pistorious Machine Co., Hicksville, NY.

d Allison-Campbell Division of American Chain \& Cable Co., Shelton, Conn. determine their modulus. This second material will be referred to as $M-2$.

To determine the modulus, each specimen was placed in an ovene for one hour at a constant temperature of $115 \mathrm{~F}$. A ChromelAlumel thermocouple (type k) was inserted into the oven and taped to the specimen, and the temperature was recorded with a potentiometer. A thermometer also was used as a check on the temperature.

The specimen reached a constant temperature of $115 \mathrm{~F}$ after one hour and it then was loaded in compression with the help of an Instron testing machine $f^{f}$ at the rate of $0.2 \mathrm{~cm} / \mathrm{min}$, and a plot of deflection versus load was recorded. Several specimens were tested in this fashion and their moduli, $E$, are shown in Table 2. Several runs were made without any samples to determine the deflection inherent within the system; such deflection was found to be negligible.

To calibrate the materials $M-1$ and $M-2$, disks, 0.25 inches thick and 1.227 inches in diameter, were sliced from virgin cylindrical specimens and loaded in diametrical compression in the oven after reaching a constant temperature of $115 \mathrm{~F}$. The governing equation for determining the fringe value for materials $M-1$ and $M-2$ is:

$$
f=\frac{8 P}{\pi D N}
$$

where $P$ is the load applied, $D$ is the diameter of the specimen, and $N$ is the fringe order at the center of the disk. The Tardy

\footnotetext{
- Type MK 2008, Hevi Duty Heating Co., Water town, Wis.

Instron Corp., Canton, Mass.
} 
TABLE 2

Optical and Mechanical Properties of Photoelastic Materials $M-1$ AND $M-2$ AT $115 \mathrm{~F}$

\begin{tabular}{|c|c|c|c|c|c|c|}
\hline & $P(\mathrm{lb})$ & $N$ & $f$ (psi-in) & $E$ (psi) & $f$ (average) & $E$ (average) \\
\hline & & & $f_{1}$ & $E_{1}$ & $f_{1}$ & $E_{1}$ \\
\hline \multirow[t]{9}{*}{$M \cdot I$} & 1.86 & 2.55 & 1.51 & 890 & & \\
\hline & 2.52 & 3.55 & 1.47 & 863 & & \\
\hline & 2.52 & 3.55 & 1.47 & 900 & & \\
\hline & 3.62 & 4.90 & 1.53 & 1,000 & 1,5075 & 950.5 \\
\hline & 3.62 & 5.0 & 1.50 & 1,040 & & \\
\hline & 3.62 & 5.0 & 1.50 & 1,010 & & \\
\hline & 3.62 & 4.9 & 1.53 & . & & \\
\hline & 4.50 & 6.0 & 1.55 & $\cdots$ & & \\
\hline & & & $f_{2}$ & $\boldsymbol{E}_{\boldsymbol{g}}$ & $f_{2}$ & $E_{2}$ \\
\hline \multirow[t]{7}{*}{$M-2$} & 4.54 & 1.7 & 5.55 & 3,760 & & \\
\hline & 5.64 & 1.95 & 6.01 & 4,040 & & \\
\hline & 5.64 & 2.0 & 5.85 & 4,035 & & \\
\hline & 7.84 & 2.75 & 5.92 & 4,200 & 6.10 & $4,082,1$ \\
\hline & 7.84 & 2.73 & 5.97 & 4,150 & & \\
\hline & 7.84 & 2.30 & 7.07 & 4,640 & & \\
\hline & 9.75 & 3.15 & 6.42 & 3,750 & & \\
\hline
\end{tabular}

method of compensation ${ }^{9}$ was used to determine the fractional fringe order at the center of each disk. Values of $f_{1}$ and $f_{2}$ are tabulated in Table 2.

PREPARATION OF THE COMPOSITE DENTAL MODEL. - The tooth prepared was a mandibular left first molar with a full crown. To prepare the tooth with a full crown preparation a silicones mold was made in which the photoelastic material $M-l$ was poured. The tooth with the full crown preparation was complete with an idealized pulp chamber. Another silicone mold was prepared in which the photoelastic material $M-2$ was poured, and this represented the gold crown casting. The steps followed in preparing the composite tooth are shown in Figure 1. The molds were prepared in sequence from 1 to 5 .

The cure cycles were carried out as indicated earlier for $M-1$ and $M-2$, and when both portions were completed they were luted using improved dental stone. $\mathbf{h}$

The first molar made of the photoelastic materials $M-1$ and $M-2$ was placed in a loading jig representing the left quadrant of the arch. This jig consisted of the first and second premolars and first and second molars, both maxillary and mandibular. Only the mandibular first molar was made of the

g Silastic A-RTV, Dow Corning, Midland, Mich.

b Duroc, Ransom and Randolph Co., Toledo, Ohio. photoelastic materials, whereas the remainder of the teeth were made of improved dental stone. $i$ The root surface of the photoelastic model was supported by a 2 to 4 $\mathrm{mm}$ layer of silicone rubber to simulate the periodontal membrane. The occlusion was that of a cusp-to-fossa relationship.

STRESS FREEZING OF THE COMPOSITE MODEL.The photoelastic composite tooth was placed in the oven for one hour at a constant temperature of $115 \mathrm{~F}$, which allowed the tooth to reach a uniform temperature. In most instances, no parasitic fringes were evident before stress freezing; if, however, parasitic fringes were observed, the model was stressannealed by heating it to $145 \mathrm{~F}$ at a rate of I F/min, and cooled to room temperature at the rate of $4 \mathrm{~F} / \mathrm{hr}$. It then was placed in the jig and was loaded. The temperature was held at $115 \mathrm{~F}$ for another hour, and then the heater of the oven was shut off and the model allowed to cool. Since the oven was well insulated the cooling was slow enough to avoid serious thermal gradients in the stress-freezing range. The composite tooth then was ready for slicing and polishing.

By use of the material system of $M-1$ and $M-2,24$ composite three-dimensional models were prepared with the following shoulder geometries: (1) the chisel-edge, (2) the chamfer, and (3) the flat shoulder with a

\footnotetext{
I Vel-Mix, Kerr Mfg. Co., Romulus, Mich.
} 

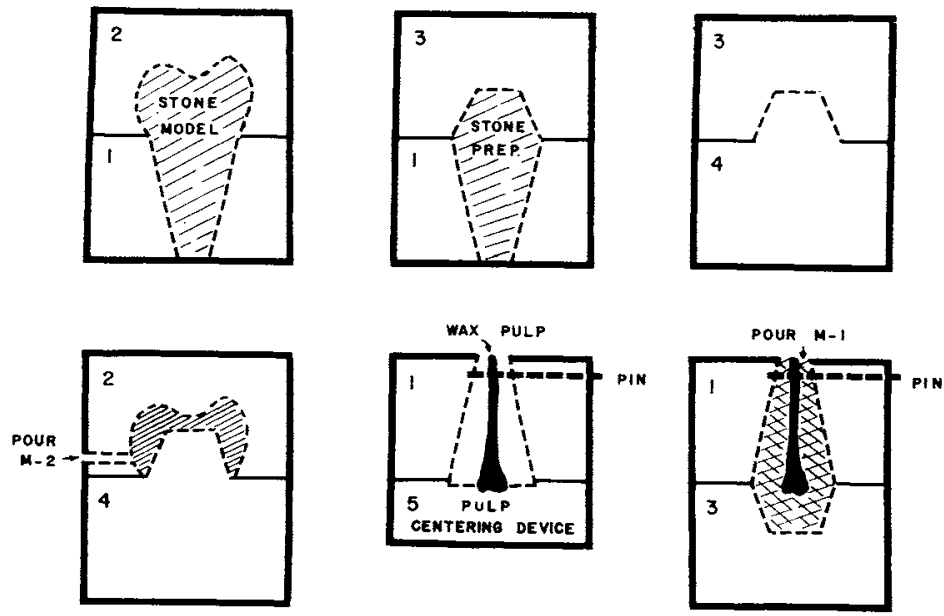

ALL WOLOS ARE A-RTV SILICONE.

FIG 1.-Steps followed in preparing composite tooth.

rounded angle at the axial wall (Fig 2). At least eight molars were prepared from each silicone mold for each geometry. The models were stress frozen at $115 \mathrm{~F}$, and an average of ten longitudinal mesial to distal slices were cut, polished, and examined in a circular polariscope. Each slice was approximately 0.125 -inch thick.

Ten values of the fringe order, $N$, were recorded along lines $A-B, C-D$, and $E-F$ as shown in Figure 2. Although all the slices of each model were examined, only two are presented here, namely the third and the fifth slices. These slices were selected because they were representative of the stress distribution which took place in areas preceding the pulp chamber and those which included the pulp chamber.

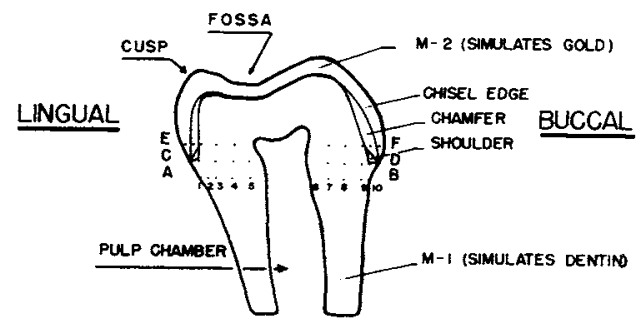

FIG 2.-Sketch of center slice of photoelastic model showing three-marginal configurations and position of lines used for detailed stress analysis.

\section{Results}

The modulus of elasticity in compression $\left(\mathrm{E}_{1}\right.$ and $\mathrm{E}_{2}$ ) of $M-1$ and $M-2$ are listed in Table 2. The average ratio of $E_{1} / E_{2}$ was $1.0: 4.3$, in other words, the ratio of the modulus at the stress-freezing temperature of the photoelastic model of the restoration and the tooth was equal to that of gold and dentin.

Typical isochromatic fringes in a slice taken from a crown with a shoulder preparation are shown in Figure 3. The variations of $N$ in slices no. 5 and 3 along line $C-D$ are plotted in Figures 4 and 5 , respectively. In Figure 6 the stress distribution in slice no. 3 resulting from point loading applied on the lingual cusp of the molar along lines $A-B$, $C-D$, and $E-F$ is given for the chisel and shoulder geometry.

\section{Discussion}

Most photoelastic materials behave in a linear fashion below a certain limit of strain. Epoxy resins behave viscoelastically, but the response in most of these materials is still linear as a function of load 10,11 and, therefore, all that is required for an analysis is a calibration as a function of time at the temperature of the test, or for the range of temperature at which the test is conducted.12 Therefore, as long as the photoelastic material is known to be linearly viscoelastic, it is 


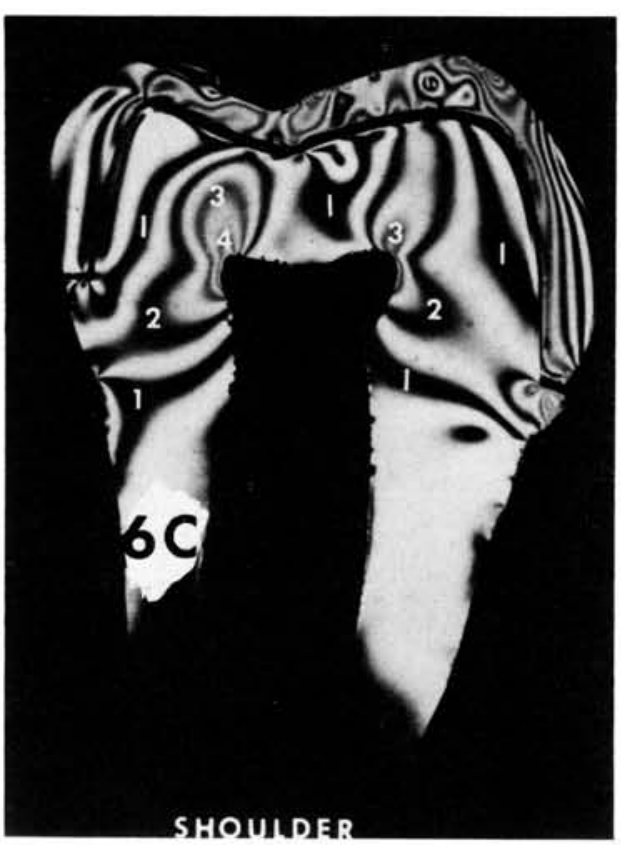

FIg 3.-Slice taken from crown with shoulder preparation exhibiting isochromatic fringes $\left(\sigma_{1}-\sigma_{2}\right)$.

not necessary to load it above the transitionzone temperature to conduct an elastic analysis. It is important, however, that the mechanical and optical properties of the material be known at the temperature in question. Values for Young's modulus of material $M-1$ varied less than those of $M-2$, and the reason was that $115 \mathrm{~F}$ was very close to the actual critical temperature of $M-1$; the same was true for values of $\mathrm{f}_{1}$ for $M-1$. The mechanical, therefore, as well as optical properties of $M-1$, were more consistent.

The advantage of this material system is that the model can be stress-frozen in a relatively short time and at a low temperature. The system also was characterized by a low exothermic reaction which made it possible to cast large models without creating residual thermal stresses. Another advantage of this system is the fact that the same silicone molds could be used to prepare up to 15 photoelastic models before it had to be discarded. Time was saved since two to three days were usually required to prepare the silicone molds, and by using one set of molds it was possible to reproduce the models accurately. The major disadvantage of the system is that the properties of epoxy mate-

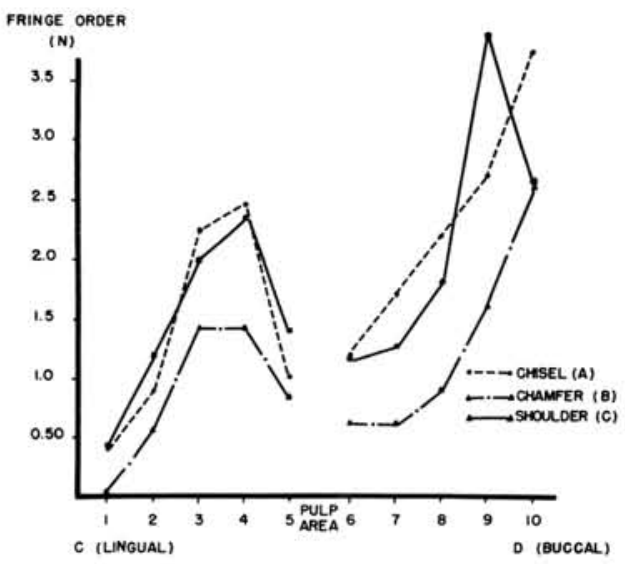

Fig 4.-Average fringe orders, $N$, in slice No. 5 of three-marginal configurations along line $C-D$.

rials are quite sensitive to small changes in temperature, and therefore considerable caution must be exercised during stress-freezing and testing.

When slices from the first molar were examined in the circular polariscope it was observed that regardless of the marginal configuration the stress distribution in the first molar was fairly symmetrical on both sides of a plane passing through the middle of the molar. In fact, the stress varied little while moving mesiodistally across the pulp chamber. Symmetry also was observed in slices taken along the long axis of the tooth. The preceding observations allowed measurements to be concentrated on slices no. 3 and 5 .

It was observed that in any slice at planes

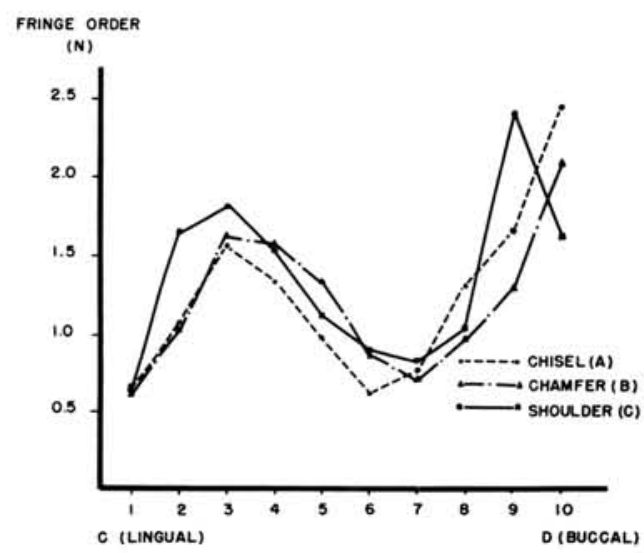

Fig 5.-Average fringe orders, $N$, in slice No. 3 of three-marginal configurations along line $C-D$. 


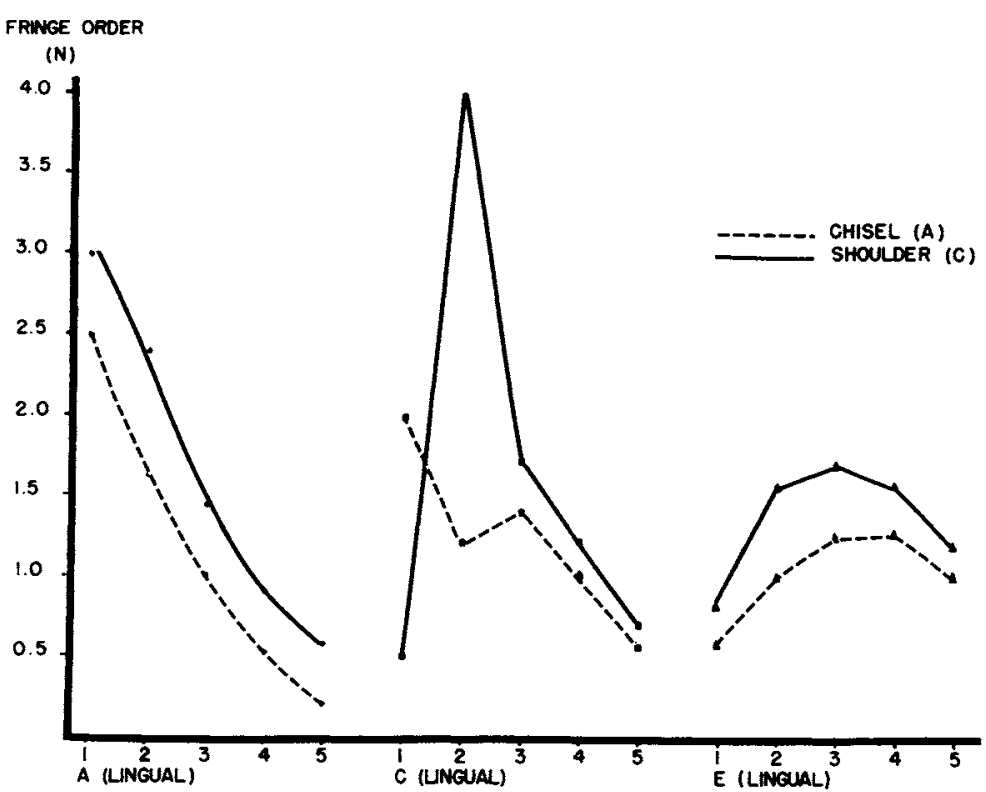

FIG 6.-Average fringe orders, $N$, in slice No. 3 resulting from point load applied on lingual cusp of molar of three-marginal configurations along lines $A-B, C-D$, and $E-F$.

remote from the areas immediately affected by the marginal changes, the shear stresses were similarly distributed regardless of the marginal configurations in question. Also, it was noticed that high shear stresses occurred in the upper two-thirds of the molar only. The lower one-third, therefore, could quite safely have been disregarded, since the shear stresses there were quite negligible.

As a result of the type of occlusion used, that is, cusp-to-fossa, the cusp on the lingual side of the molar was under less shear stress, and therefore, the shear stresses at the margin on the lingual side were lower than those on the buccal side. As can be seen in Figure 6 , not much difference occurred in $N$, which is directly proportional to the shear stress, between the chisel edge and the shoulder geometry, except at point 9, where $N$ was higher for the shoulder geometry. In contrast, the chamfer geometry exhibited lower shear stresses at all points along line $C-D$. In Figure 4, relatively high shear stresses occurred at points 3 and 4; this was caused mainly by the maxillary tooth contacting the mandibular first molar at the fossa, above the pulp chamber. Also in Figure 4, point 10 was a high shear stress area, which was mainly a result of the sudden change in the outer morphology of the molar. It should be noted (Figs 4 and 5) that the stress distributions in all three geometrical configurations followed much the same pattern, except in the immediate vicinity of a marginal change. For example, in Figure 6, chisel edge as well as shoulder models were loaded with a point load on the lingual cusp of the molar, and it can be seen that the same stress pattern occurred in both, except at point no. 2, which was located directly under the shoulder, where $N$ was approximately three times higher for the shoulder compared to the chisel edge geometry.

When the slices were examined in the polariscope, it was assumed that $\sigma_{3}$ was constant. This is a reasonable assumption, since the thickness was small compared to the other two dimensions of the slice. Also, when the slice was observed in the polariscope all recordings were made on the mesial surface, but these were not significantly different from the values of $N$ on the distal surface as long as the slices were thin; this supports the previous assumption.

In a related study 13 based on earlier observations of the symmetry in the shear stress, an axisymmetric model was prepared, subjected to a 100-1b load, and analyzed both photoelastically and by the finite element method. The finite element method is a nu- 
merical analysis method and it has the advantage of providing information about the complete state of stress in a body. The maximum shear stresses obtained both by the photoelastic and finite element methods at predetermined locations in the axisymmetric model compared favorably and in most instances, the discrepancy was less than $10 \%$. Thus, the axisymmetric finite element model complemented the findings of the photoelastic model. Furthermore, since the process of separating the stresses (that is finding $\sigma_{x}, \sigma_{y}, \sigma_{1}, o_{2}$, and so forth) in three-dimensional photoelasticity is quite cumbersome, the finite element method was more comprehensive and helped clarify the results obtained by the photoelastic method.

\section{Conclusions}

A method was developed by which a wide range of values of Young's Modulus for photoelastic materials could be obtained at the same stress freezing temperature. Two photoelastic materials were selected whose moduli, as well as Poisson's ratios, at the stress freezing temperature were approximately equal to that of dentin or gold. It was found that the change in marginal configuration of the crown affected the stress distribution only in the regions in the immediate vicinity of such change, so that the areas of interest were located at the level of the gingiva or subgingiva. Also, because of the cusp-to-fossa type of occlusion, more shearing stresses were concentrated on the buccal than the lingual area of the models. Symmetry in the shear stress was apparent in a mesial or distal direction from a plane at the center of the photoelastic molar. Symmetry also was present in consecutive sections along the long axis of the tooth model. The lower third of the tooth was relatively free of stress but significant shearing stresses existed at planes remote from the points of contact of the photoelastic molar. The chamfer geometry exhibited the least amount of shear stress at the margins, followed by the chisel edge and the shoulder, which did not differ much except at a point immediately under the shoulder. When normal occlusion was achieved, that is, absence of premature contact, there did not seem to be a major change in the distribution of the shear stress in the tooth model, regardless of the type of marginal configuration. The distribution of the shear stress for the shoulder geometry became important in cases of malocclusion, or in cases of concentrated point loading at the cusp.

\section{References}

1. Walton, C.B., and Leven, M.M.: A Preliminary Report of Photoelastic Tests of Strain Patterns within Jacket Crowns, $J A D A$ 50: 44-48, 1955.

2. Johnson, E.W.: A Three-Dimensional Photoelastic Investigation of Stress Concentration in Operably Deformed Human Teeth, MS dissertation, University of Alberta, 1965.

3. Johnson, E.W.; Castaldi, C.R.; GaU, D.J.; and WYsocki, G.P.: Stress Pattern Variations in Operatively Prepared Human Teeth, Studied by Three-Dimensional Photoelasticity, J Dent Res 47: 548-558, 1968.

4. El-Ebrashi, M.K.; Craig, R.G.; and Peyton, F.A.: Experimental Stress Analysis of Dental Restorations: III. The Concept of the Geometry of Proximal Margins, $J$ Prosthet Dent 22: 333-345, 1969.

5. El-Ebrashi, M.K.; Craig, R.G.; and Peyton, F.A.: Experimental Stress Analysis of Dental Restorations: IV. The Concept of Parallelism of Axial Walls, $J$ Prosthet Dent 22: 346-353, 1969.

6. El-Ebrashi, M.K.; Craig, R.G.; and Peyton, F.A.: Experimental Stress Analysis of Dental Restorations: V. The Concept of OCclusal Reduction and Pins, $J$ Prosthet Dent 22: 565-577, 1969.

7. El-Ebrashi, M.K.; Craig, R.G.; and Peyton, F.A.: Experimental Stress Analysis of Dental Restorations: VI. The Concept of Proximal Reduction in Compound Restorations, $J$ Prosthet Dent 22: 663-670, 1969.

8. El-Ebrashi, M.K.; Craig, R.G.; and Peyton, F.A.: Experimental Stress Analysis of Den. tal Restorations: VII. Structural Design and Stress Analysis of Fixed Partial Dentures, $J$ Prosthet Dent 23: 177-186, 1970.

9. Dally, J.W., and Riley, W.F.: Experimental stress analysis, New York: McGraw-Hill, 1965.

10. Theocries, P.S., and Mylonas, C.: Viscoelastic Effects in Birefringent Coatings, $J$ Appl Mech 28:601-607, 1961.

11. Brinson, H.F.: Mechanical and Optical Viscoelastic Characterization of Hysol 4290, J Exp Mech 8: 561-566, 1968.

12. Durelli, A.J., and LAKE, R.L.: Some Unorthodox Procedures in Photoelasticity, Proc Soc Exp Stress Analysis IX: 97-122, 1951.

13. Farah, J.W.; Craig, R.G., and Sikarskie, D.L.: Photoelastic and Finite Element Stress Analysis of a Restored Axisymmetric First Molar, J Biomech 6: 511-520, 1973. 